\title{
Expression of Viral DNA Polymerase Gene in Larvae of the Silkworm, Bombyx mori (Lepidoptera: Bombycidae), during Infection with Nuclear Polyhedrosis Virus
}

\author{
Sudawan ChaeYchomsRi, Motoko IKedA and Michihiro Kobayashi \\ Iaboratory of Sericulture and Entomoresources, School of Agricultural Science, Nagoya University, \\ Chikusa-ku, Nagoya 464-01, Japan
}

(Reccived 17 January 1995; Accepted 24 February 1995)

\begin{abstract}
Expression of viral DNA polymerase gene ( $p o l)$ was examined in the midgut, fat body, silkgland and remaining carcass of larvae of the silkworm, Bombyx mori, infected with $B$. mor nuclear polyhedrosis virus (BmSNPV). Northern blot analysis detected a prominent viral pol transcript of approximately $3 \mathrm{~kb}$ and several other less prominent transcripts in these tissues. Mapping of the $5^{\prime}$ end by RNase protection assay showed that the 3-kb pol transcript detected in the Northern blot analysis consisted of two species. These two species corresponded to the major and the largest transcripts, respectively, among seven viral pol transcripts identified previously in the BmSNPV-infected BM-N cells, demonstrating no viral pol transcripts unique to the infected tissues. Expression of each transcript varied considerably among tissues and with postinfection time. The abundance of overall pol transcripts coincided with those of DNA polymerase protein, viral DNA, viral polypeptides and polyhedrin in these tissues, with the exception of the carcass. These results suggest that the expression of viral pol transcripts is regulated differentially among tissues and during infection. They also suggest a possible role of viral early gene expression or viral DNA synthesis in the regulation of late and very late gene expression.

Key words: silkworm larva, nuclcar polyhedrosis virus, DNA polymerase, gene expression, Bombyx mori
\end{abstract}

\section{INTRODUCTION}

Bombyx mori nuclear polyhedrosis virus (BmSNPV), the type species of the family Baculoviridae subgenus single nucleocapsid NPV (FrANCKI et al., 1991), is an infectious agent that causes acute disease in the silkworm, B. mori. This virus contains a doublestranded, covalently closed circular DNA genome of approximately $125 \mathrm{kbp}$ (IATROU et al., 1985; IrzukA et al., 1987; MAEDA and MNJIM , 1990) which is associated with a highly basic (arginine-rich) protein with a molecular weight (MW) of approximately 7,900 (7.9K) (MAEDA et al., 1991). The majority of BmSNPV nucleocapsids are singly enveloped to form rod-shaped virus particles or virions consisting of at least 80 structural polypeptides, as identified by two-dimensional high-resolution electrophoresis (Sugrmori et al., 1990). The virions are embedded within a crystalline matrix or polyhedron, the major structural component of which is a single protein, designated as polyhedrin, with an approximate MW of 31K (IATrou et al., 1985; Sugimori et al., 1990).

In cultured cells infected with baculoviruses, viral gene expression has been shown to be regulated as an ordered cascade at the level of transcription, and viral genes are currently divided into four classes according to the time and manner of expression: immediate 
early, delayed early, late, and very late (cf., FrIESEN and MILLER, 1986). Immediate early and delayed early genes are transcribed before initiation of viral DNA replication by an $\alpha$ amanitin-sensitive RNA polymerase, apparently host RNA polymerase II (Fuchs et al., 1983; HUH and WEAVER, 1990). Immediate early genes, which largely encode regulatory proteins for the expression of later genes, are independent of prior expression of any viral genes, whereas the expression of delayed early genes requires one or more regulatory proteins previously expressed from immediate early genes. Late genes, most of which encode viral structural proteins, are transcribed concomitant with or after replication of the viral genome by an $\alpha$-amanitin-resistant RNA polymerase (FucHs et al., 1983; HuH and WEAVER, 1990). The transcription of very late genes begins well after the onset of late gene transcription, and continues until a very late postinfection time when most late genes have ceased transcription. Little is known of baculovirus gene expression in the tissues of infected insects.

Baculovirus DNA replication is an essential prerequisite for the production of progeny virions, and seems to be mediated directly or indirectly by the expression of several early viral genes. The expression products of these early viral genes presumably responsible for the baculovirus DNA replication include a DNA helicase (LU and CARSTENS, 1991), a proliferating cell nuclear antigen (PCNA)-like protein (CRAwFORd and Miller, 1988; O'Reilly et al., 1989), and a DNA polymerase (TOMALSKI et al., 1988; BJORNSON et al., 1992; ChAEYchomsRi et al., 1995). Although direct evidence has not been demonstrated, the fact that a unique DNA polymerase with distinct properties from those of cellular DNA polymerases is induced in baculovirus-infected cell culture and whole insects (KeLLY, 1981; Miller et al., 1981; WANG and KeLly, 1983; MikHailov et al., 1986) strongly suggests an essential role of virus-encoded DNA polymerase in baculovirus DNA replication. BmSNPV DNA polymerase gene (pol) as with Autographa californica NPV (AcMNPV) pol has been shown to lack canonical TATAA and CCAAT elements in the upstream region and initiate transcription at multiple sites in cultured cells (TOMALSKI et al., 1988; CHAEYCHOMSRI et al., 1995). It has also been demonstrated in BmSNPV and AcMNPV that cycloheximide, an inhibitor of protein synthesis, does not inhibit, but delays, the expression of pol, whereas aphidicolin, an inhibitor of nuclear DNA replication, lowers the steady-state level of pol transcripts markedly (TOMALSKI et al., 1988; CHAEYCHOMSRI et al., 1995). These findings in cultured cells indicate that the gene expression of baculovirus pol is regulated by a complex and unique mechanism.

In the present study, we examined baculovirus pol expression in the fat body, midgut, silkgland and remaining carcass from silkworm larvae infected with BmSNPV. Accumulation of viral DNA and viral polypeptides was also examined in infected tissues to monitor the overall changes in the BmSNPV virion components during virus infection. Transcriptional analyses showed that among seven species of viral pol transcripts identified in BmSNPV-infected BM-N cells (ChAEYchomsRI et al., 1995), only two species were expressed in infected tissues. It was also shown that expression of these two pol transcripts occurred in a tissue-specific manner.

\section{MATERIALS AND METHODS}

Insect and virus. The silkworm, Bombyx mori, used was a hybrid race between Kinshu and Showa, and larvae were reared aseptically on an artificial diet (Kyodo Shiryo, Yokohama, Japan) at $25^{\circ} \mathrm{C}$. A plaque-purified isolate, N9, of BmSNPV (NAGAMINE et al., 
1989) was used. The polyhedra for inoculation were propagated in BM-N cells as previously described (NAGAMINE et al., 1991), and partially purified by washing several times with

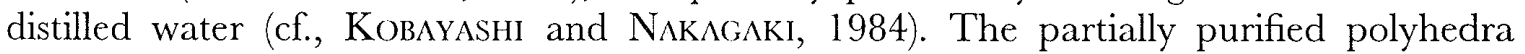
$\left(2.5 \times 10^{3}\right.$ in $5 \mathrm{ml}$ of sterile water) were applied to the surface of the artificial diet (area approximately $180 \mathrm{~cm}^{2}$ and wet weight approximately $100 \mathrm{~g}$ ), and 40 newly ecdysed fifth instar larvae were fed for $24 \mathrm{~h}$ at $23^{\circ} \mathrm{C}$ on the artificial diet contaminated with polyhedra. Control larvae were fed on an artificial diet to which the same volume of sterile water was applied. Although the optimal temperature of the development of nuclear polyhedrosis has been shown to be around $30^{\circ} \mathrm{G}$ (KoBAyashi and ChAeychomsri, 1993), infected and uninfected larvae were incubated at $23^{\circ} \mathrm{C}$ to allow the infection to proceed slowly. The mortality of the infected larvae from nuclear polyhedrosis was 58 and $100 \%$ at 7 and 8 days postinfection (pi), respectively; surviving larvae were used for analysis at 7 days pi.

Isolation of cellular RNA and Northern blot analysis. Cellular RNA was extracted from tissues by guanidinium thiocyanate solubilization (CHOMCZYNSKI and SACCHI, 1987), and poly $(\mathrm{A})^{+}$RNA was selected with Oligotex-dT30 (Roche) according to the manufacturer's instructions. Five micrograms of poly $(\mathrm{A})^{+} \mathrm{RNA}$ was denatured and electrophoresed on a $0.8 \%$ formaldehyde-denaturing SeaKem agarose gel (FMC Corp.). The RNA on the gel was transferred onto a Hybond- $\mathrm{N}^{+}$nylon membrane (Amersham) and hybridized with a ${ }^{32} \mathrm{P}-$ labeled BmSNPV DNA pol probe under the conditions described by SAMBROOK et al. (1989). The DNA probe was prepared from the 2.2-kbp Pst $\mathrm{I}$-SmaI fragment of the pol (cf., ChneYchomsri et al., 1995) and labeled with $\left[\alpha-{ }^{32} \mathrm{P}\right] \mathrm{dCTP}$ (Dupont NEN) by the rediprime DNA labeling system (Amersham).

Isolation of total cellular DNA and slot blot analysis of viral DNA. Total cellular DNA was prepared from tissues according to the method of VAN BEEK et al. (1990) with slight modifications. Midgut, fat body, silkgland, and carcass were each dissected out from infected larvae at different times pi, and homogenized in $5 \mathrm{vol}$. (v/w) of ice-cold TE $(10 \mathrm{~mm}$ Tris$\mathrm{HCl}, \mathrm{pH}$ 8.0, 1 mM EDTA) using a Hitachi HG 30 homogenizer. The homogenates were centrifuged at 5,000 $\times g$ for 3 min to precipitate cell debris, and proteinase $\mathrm{K}$ and SDS were added to the supernatants at final concentrations of $1 \mathrm{mg} / \mathrm{ml}$ and $0.25 \%$, respectively. The suspensions were incubated overnight at $37^{\circ} \mathrm{C}$, and then extracted three times with TEsaturated phenol, once with phenol/chloroform $(1: 1, \mathrm{v} / \mathrm{v})$, and once with chloroform. DNA was precipitated with $0.1 \mathrm{vol}$. (v/v) of $3 \mathrm{M}$ sodium acetate, $\mathrm{pH} 5.2$, and $2.5 \mathrm{vol} .(\mathrm{v} / \mathrm{v})$ of cold ethanol. The precipitates were collected by centrifugation, dried and resuspended in TE. DNA samples containing a total of $200 \mathrm{ng}$ DNA were blotted onto a Hybond- ${ }^{+}$ membrane in a MilliBlot transfer apparatus (Millipore). The blots were hybridized to either ${ }^{32}$ P-labeled BmSNPV genomic DNA (partially digested with Sau3AI) or the DNA pol probe previously prepared for the Northern blot analysis (see above).

RNase protection assay. Mapping of the 5' end of BmSNPV pol transcripts by RNase protection assay was conducted as previously described (CHАEYCHOMSRI et al., 1995). Briefly, poly $(\mathrm{A})^{+}$RNA from infected tissues and ${ }^{32}$ P-labeled RNA probe ER3 were hybridized overnight at $45^{\circ} \mathrm{C}$, followed by treatment with RNase solution as recommended by the manufacturer (Ambion). The resultant RNase-resistant fragments were analyzed by a sequencing gel and visualized by autoradiography. The radiolabeled RNA probe ER3 was prepared by the transcription of linearized pSP72 (Promega) containing the BmSNPV pol DNA fragment in the presence of $\left[\alpha-{ }^{32} \mathrm{P}\right] \mathrm{CTP}$. For transcription, the in vitro transcription system with T7 RNA polymerase (Promega) was used.

Expression of DNA polymerase fusion proteins and production of anti-DNA polymerase 
antisera. The 927-bp PstI-ClaI and 1039-bp EcoRI-ClaI DNA fragments of the pol (cf., ChaEYChOMSRI et al., 1995) were each subcloned into the PstI-HindIII and EcoRI-XbaI sites of the pMAL-c2 expression vector (New England Biolabs), to construct plasmids pXP10 and pXE4, respectively. Constructs of pXP10 and pXE4 were introduced into Escherichia coli XLl-Blue (Stratagene). Bacteria were grown at $37^{\circ} \mathrm{C}$ to an absorbance of 1.0 at $600 \mathrm{~nm}$. The fusion product of maltose binding protein (MBP) and BmSNPV DNA polymerase protein was expressed by induction with isopropyl- $\beta$-D-thiogalactopyranoside (IPTG) at a final concentration of $0.3 \mathrm{~mm}$. After $1 \mathrm{~h}$ of induction, the bacteria were harvested and purified by affinity chromatography with an amylose column (New England Biolabs). The purified fusion protein was emulsified in Freund's complete adjuvant and injected into mice for immunization.

Sodium dodecyl sulfate (SDS)-polyacrylamide gel electrophoresis (PAGE) and Western blot analysis. Protein samples solubilized in the gel loading buffer $(62.5 \mathrm{mM}$ Tris- $\mathrm{HCl}, \mathrm{pH} 6.8,2 \% \mathrm{SDS}$, $5 \% 2$-mercaptoethanol, $10 \%$ glycerol) were resolved on 10 or $12.5 \%$ SDS-polyacrylamide gels according to the method of LaEmmL (1970). The gels were either stained with Coomassie brilliant blue or electroblotted with Horizblot (Atto, Tokyo) onto a nitrocellulose membrane (Advantec Toyo, Osaka, Japan) at room temperature for $70 \mathrm{~min}$ at a constant current of $200 \mathrm{~mA}$. Western blots were incubated overnight with gentle rocking at $4^{\circ} \mathrm{C}$ with the anti-DNA polymerase antiserum at a 1:500 dilution, and then reacted with ${ }^{125}$ I-labeled goat anti-mouse IgG (ICN Biomedicals). For identification of virus-specific polypeptides and polyhedrin, antisera against polyhedra-derived virions and polyhedrin, respectively, prepared in rabbits (KOBAYASHI et al., 1990) were used as primary antibodies. Antibody-antigen complexes were detected using ${ }^{125}$ I-labeled goat anti-rabbit IgG (ICN Biomedicals). Immunoreactivity was visualized and quantified by an imaging analyzer (BAS 2000, Fuji Photo
Film).

\section{RESULTS}

\section{Viral pol expression during infection}

Two sets of experiments were performed to analyze the viral pol transcripts in silkworm larvae infected with BmSNPV. In the first set, Northern blots of poly $(\mathrm{A})^{+}$RNA from the midgut, fat body, silkgland and carcass of BmSNPV-infected larvae were hybridized to the DNA probe from a specific region of the pol. As shown in Fig. 1, a major transcript of approximately $3 \mathrm{~kb}$ was detected in infected tissues. The size of the transcript detected in the present experiment was consistent with that of transcripts previously observed in BmSNPV-infected BM-N cells (cf., CHAEYchOMSRI et al., 1995). Accumulation of 3-kb pol transcript was abundant in the fat body and carcass, less abundant in the midgut, and barely detectable in the silkgland. In the fat body, the pol transcript was first detected at 4 days pi, maximally present at 5 days pi, declined by 6 days pi, and remained at this level at 7 days pi, whereas the pol transcript in the carcass was first detected at 4 days pi, maintained constant until 6 days pi, and declined at 7 days pi. Expression of the pol transcripts in the midgut was first observed at 6 days pi at a low level and was still present at 7 days pi.

In addition to the 3-kb pol transcript, a less prominent BmNPV pol transcript of approximately $6 \mathrm{~kb}$ was present in the fat body, midgut and carcass at 6 and 7 days pi, whereas a pol transcript of approximately $4 \mathrm{~kb}$ was observed in the fat body and carcass. In the carcass, two very faint bands of pol transcripts of approximately 10 and $7 \mathrm{~kb}$ were also detectable (Fig. 1). Transcripts with sizes far smaller than $3 \mathrm{~kb}$, that were detectable in the 


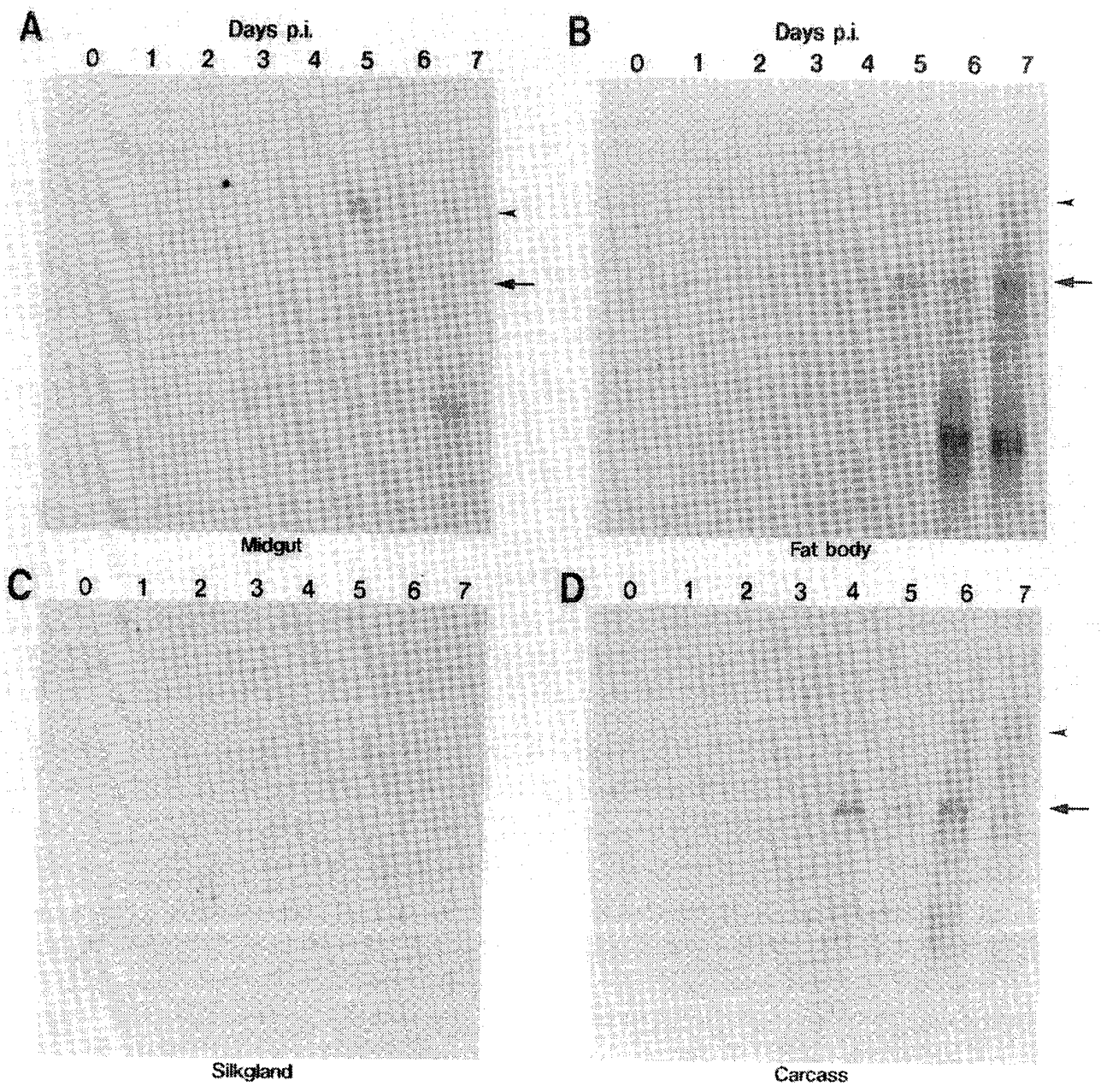

Fig. 1. Northern blot analysis of the pol transcripts in BmSNPV-infected larval tissues. Poly $(\mathrm{A})^{+}$RNA $(5 \mu \mathrm{g})$ from the infected midgut (A), fat body (B), silkgland (C), and carcass (D) at the various times pi indicated above the lanes was separated on a formaldehyde denaturing SeaKem agarose gel, blotted onto a nylon membrane, and hybridized with ${ }^{32} \mathrm{P}$-labeled DNA probe derived from the Pstl-SmaI fragment of the BmSNPV pol. Arrow indicates the position of the major transcript of approximatcly $3 \mathrm{~kb}$, whereas the arrowhead indicates the second major transcript of about $6 \mathrm{~kb}$.

fat body, midgut and carcass, probably represent artifacts generated by degradation during the experiments.

In the second set of experiments, an RNase protection assay was performed to examine whether the initiation sites of BmSNPV pol transcripts differed among tissues and during infection. When the RNase protection assay was carried out using the ER3 RNA probe and the poly $(\mathrm{A})^{+}$RNA from the midgut, fat body, silkgland and carcass of BmSNPV-infected larvae, two protected fragments of 180 and 309 nucleotides (nt) in length were detected (Fig. 2), and increasing the exposure time of the autoradiography to $120 \mathrm{~h}$ (usually $48 \mathrm{~h}$ ) did not increase the number of protected fragments. This was in contrast to seven protected fragments in BmSNPV-infected BM-N cells (ChAEychomsRi et al., 1995). The 180- and 309-nt fragments have been identified in BmSNPV-infected BM-N cells to be the major and the 


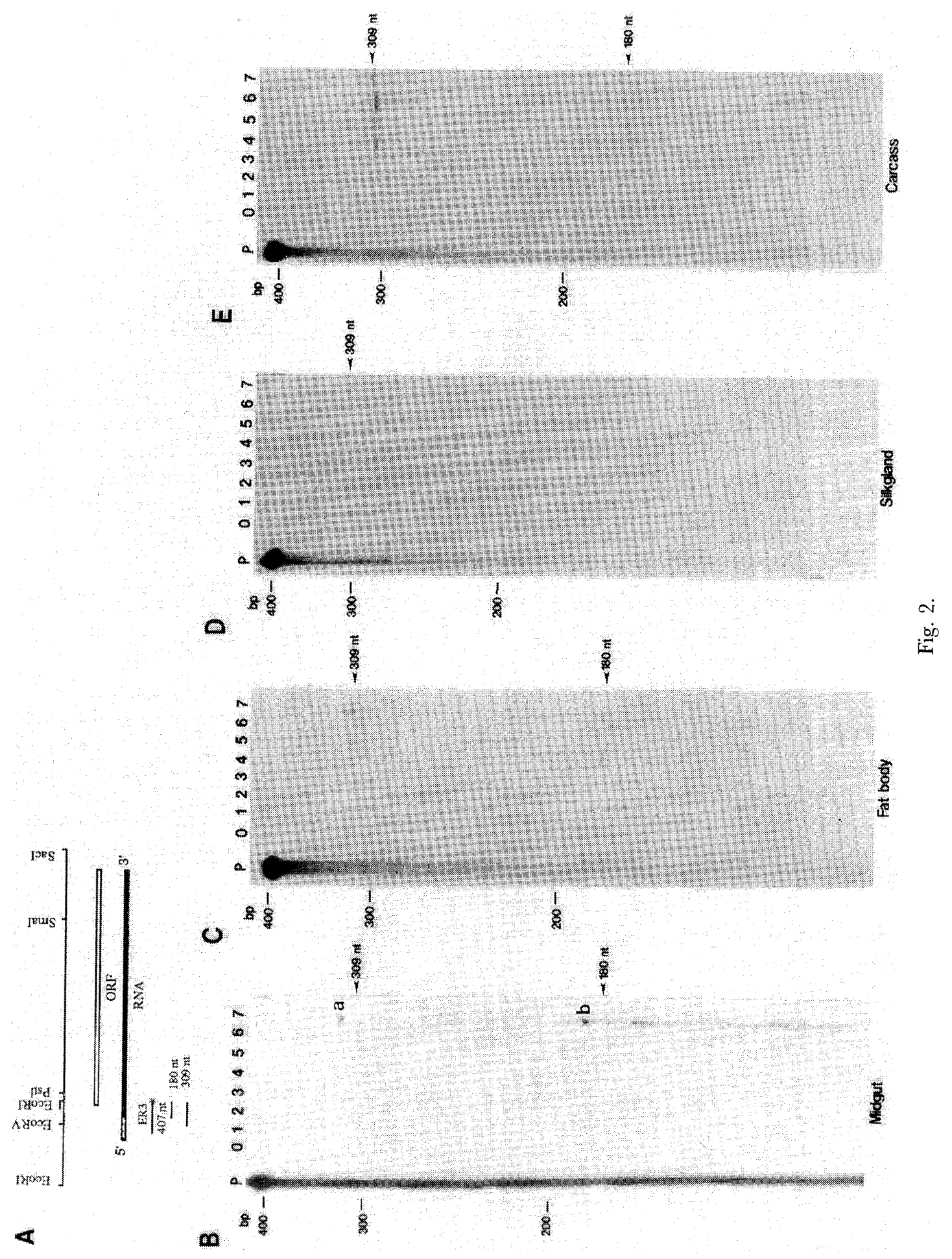


largest transcripts which place the initiation sites at -119 (-119 transcript) and $-334(-334$ transcript), respectively, relative to the translational initiation codon (CHALYCHOMSRI et al., 1995). The number and initiation site of the BmNPV pol transcripts in these tissues were confirmed by primer extension analysis (data not shown).

The kinetics of the accumulation of -119 and -334 transcripts differed among infected tissues and with the times pi. In the fat body, the -119 transcript was first observed at 4 days pi, increased at 5 days pi and declined from 6 to 7 days pi, whereas the -334 transcript was detected at a low level at 4 days pi, increased at 5 days pi, and remained constant until 7 days pi (Fig. 2). In the carcass, the -119 transcript was first observed at 3 days pi, abundantly expressed at 4 and 5 days pi, and declined to 7 days pi, whereas the -334 transcript was first observed at the same abundance as that of -119 transcript at 3 days pi, reached a maximum at 4 days pi, and remained at this level until 7 days pi. In the midgut, the temporal pattern of the -119 and -334 transcripts was similar. These two transcripts were both weakly detected at 5 days pi, and increased slightly by 7 days pi. In the silkgland, the -334 transcript was detected at 6 and 7 days pi only after prolonged exposure of the autoradiograph, whereas the -119 transcript was undetectable under the conditions utilized (Fig. 2).

\section{Viral DNA polymerase protein accumulation during infection}

To identify the viral DNA polymerase protein, protein samples from infected tissues were resolved on 10\% SDS-polyacrylamide gels and probed with antiserum against BmSNPV DNA polymerase. The Western blot analysis detected, among several nonspecific bands, a protein band that was not observed in the uninfected tissues (Fig. 3). This protein had an approximate MW of $125 \mathrm{~K}$, that was roughly comparable to the $115 \mathrm{~K}$ of the BmSNPV DNA polymerase predicted from the open reading frame of pol (cf., Chasychomsri et al., 1995), and was detected in common in the fat body, midgut and carcass at later stages of infection. Based on these observations, we thought it reasonable to conclude that the protein identified in the Western blot analysis was from the viral DNA polymerase. The DNA polymerase protein was first detected at 5 or 6 days pi in the midgut, fat body and carcass (Fig. 3). The accumulation of DNA polymerase protein increased steadily through 7 days pi in the midgut, while in the fat body, it increased to 6 days pi but decreased at 7 days pi. This decrease in DNA polymerase protein in the fat body coincided with the decrease in viral DNA (cf., Fig. 4), suggesting a selective disintegration of severely infected cells into the haemocoel. In the carcass, DNA polymerase protein remained constant at a low level until 7 days pi. No detectable amount of DNA polymerase protein accumulated in the silkgland (Fig. 3).

Fig. 2. Mapping of the $5^{\prime}$ end of the pol transcripts in the BmSNPV-infected larval tissues by RNase protection assay. (A) Location of the probe used to map the $5^{\prime}$ end of the transcripts. Probe ER3 derived from in vitro transcription was $5^{\prime}$ end labeled at the XhoI site in vector pSP72 containing the BmSNPV pol DNA fragment. The position of the label is indicated by an asterisk. (B) to (E) RNase protection analysis of the $5^{\prime}$ end of pol transcripts. Poly(A)+ RNA (2 $\left.\mu \mathrm{g}\right)$ was prepared from BmSNPV-infected midgut $(B)$, fat body $(\mathrm{C})$, silkgland $(\mathrm{D})$, and carcass $(\mathrm{E})$ at the various times pi as indicated above the lanes. RNA was hybridized to the ER 3 probe and subjected to digestion with RNase. The RNase-resistant products were resolved on a $5 \%$ polyacrylamide sequencing gel along with the undigested probe (lane P). Molecular weight markers are indicated on the left. The numbers and arrowheads indicate the size of the protected fragments. For technical reasons, the mobility of the 309-nt (a) and 180-nt (b) protected fragments in the 7 day pi lane of panel B was relatively slower than that observed in other lanes. 

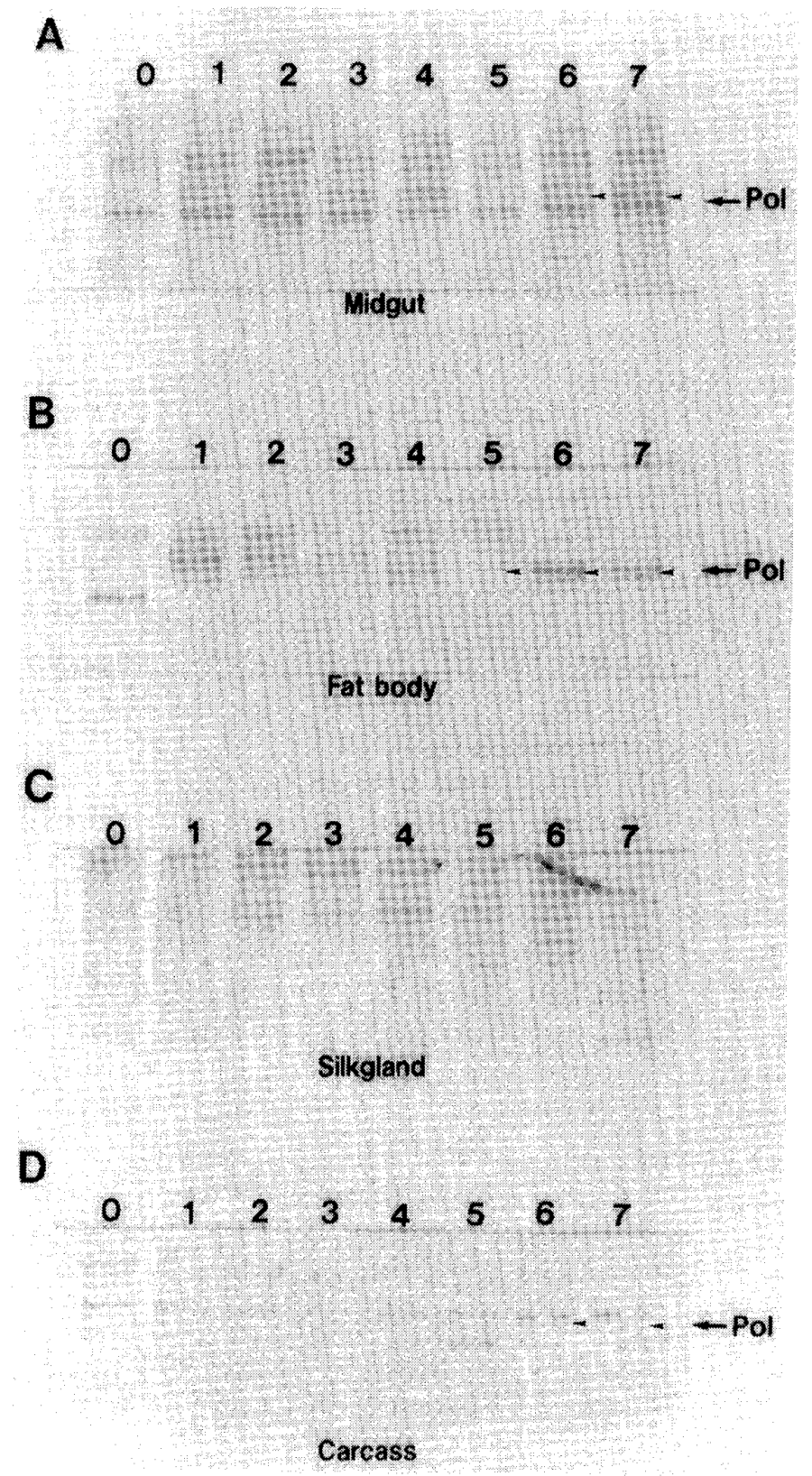

Fig. 3. Western blot analysis of DNA polymerase polypeptide in the BmSNPV-infected larval tissues. Samples of total proteins $(50 \mu \mathrm{g})$ from the midgut $(\mathrm{A})$, fat body $(\mathrm{B})$, silkgland $(\mathrm{C})$ and carcass $(\mathrm{D})$ at various times pi were resolved on $10 \%$ SDS-polyacrylamide gels, electroblotted onto nitrocellulose membranes, and reacted with anti-DNA polymerase antiserum prepared in a mouse. Antibody-antigen complexes were detected by ${ }^{125}$ I-labeled goat anti-mouse $\mathrm{IgG}$, and visualized by an imaging analyzer. The band of DNA polymerase protein is indicated by an arrowhead. The numbers above the lanes represent the days pi.

\section{Viral DNA accumulation during infection}

Viral DNA accumulation in infected tissues was analyzed by slot blot hybridization. Total cellular DNA from the midgut, fat body, silkgland, and carcass of the BmSNPVinfected larvae was blotted onto a nylon membrane and hybridized to a BmSNPV pol 


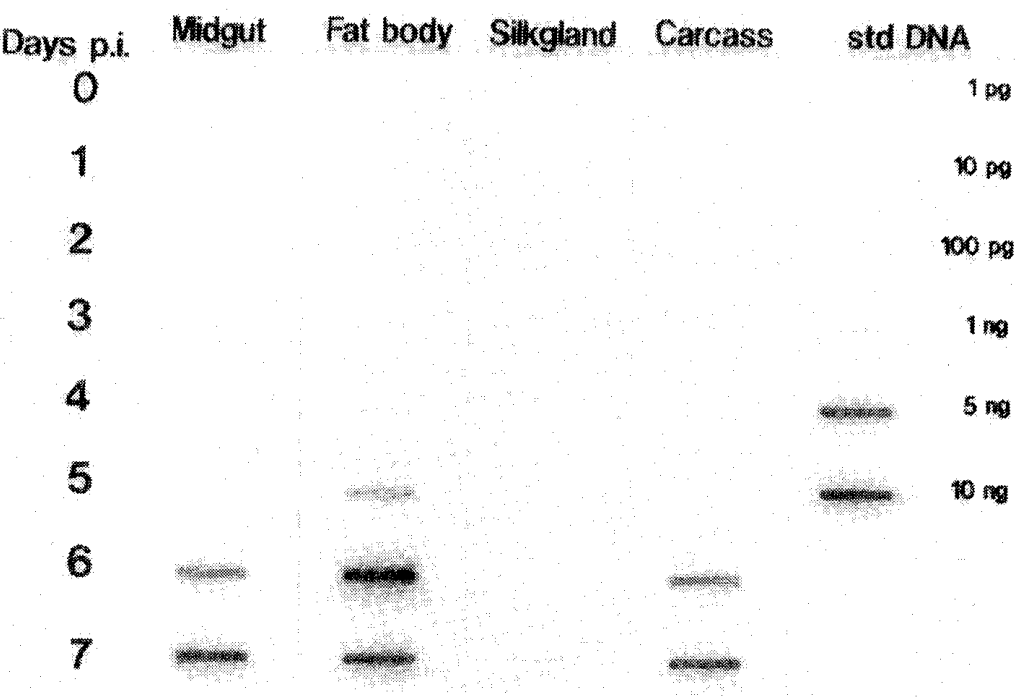

Fig. 4. Slot blot analysis of viral DNA in BmSNPV-infected larval tissues. Total DNA (200 ng) from infected midgut, fat body, silkgland, and carcass at various times pi was spotted onto a nylon membranc and hybridized with ${ }^{32}$ P-labeled BmSNPV pol DNA probe. BmSNPV genomic DNA of known amount was also spotted as a standard. The numbers on the left represent days pi.

probe. In the fat body, viral DNA was first detected at 4 days pi, reached a maximum at 6 days pi, and decreased slightly at 7 days pi (Fig. 4). In the midgut and carcass, viral DNA was detected at 6 days pi and increased slightly at 7 days pi, although the amount and rate of increase of the viral DNA in these tissues were significantly lower than those in the fat body. Viral DNA was detected in very low quantities in the silkgland at 6 and 7 days pi (Fig. 4).

Hybridization of the same DNA preparations to the probe from BmSNPV genomic DNA partially digested with Sau3AI yielded essentially the same results except that the intensity of the hybridization was higher than that of the pol probe (data not shown).

\section{Viral polypeptides and polyhedrin accumulation during infection}

Alterations of overall polypeptide patterns in BmSNPV-infected larval tissues were examined by SDS-PAGE. The gels stained with Coomassie brilliant blue showed that the protein profiles changed quantitatively and qualitatively in larval tissues during infection with BmSNPV (data not shown). To examine the accumulation of viral structural polypeptides in BmSNPV-infected tissues, samples identical to those used for SDS-PAGE analysis were resolved on parallel polyacrylamide gels and subjected to Western blot analysis with antiserum against BmSNPV virions. The Western blot analysis showed that a number of viral polypeptides accumulated in the infected tissues (Fig. 5). In the midgut, fat body, and carcass, polypeptides with approximate MWs of $89 \mathrm{~K}, 78 \mathrm{~K}, 68 \mathrm{~K}, 56 \mathrm{~K}, 51 \mathrm{~K}, 39 \mathrm{~K}, 16.5 \mathrm{~K}$ and $16 \mathrm{~K}$ were detected. Polypeptides of $91 \mathrm{~K}, 58 \mathrm{~K}$ and $40 \mathrm{~K}$ appeared in the fat body and carcass, and a $22 \mathrm{~K}$ polypeptide appeared in the midgut and fat body. Polypeptides of $37 \mathrm{~K}$, $23 \mathrm{~K}$ and $21.5 \mathrm{~K}$ were specifically detected in the fat body. A $16.5 \mathrm{~K}$ polypeptide was the only viral polypeptide detected in the silkgland. Among the viral polypeptides detected in BmSNPV-infected tissues, polypeptides of $78 \mathrm{~K}, 39 \mathrm{~K}, 16.5 \mathrm{~K}$ and $16 \mathrm{~K}$ were the major polypeptides. A viral polypeptide with an approximate MW of $16.5 \mathrm{~K}$ was first detected at 4 days pi in the fat body, at 5 days pi in the carcass and at 6 days pi in the midgut and 


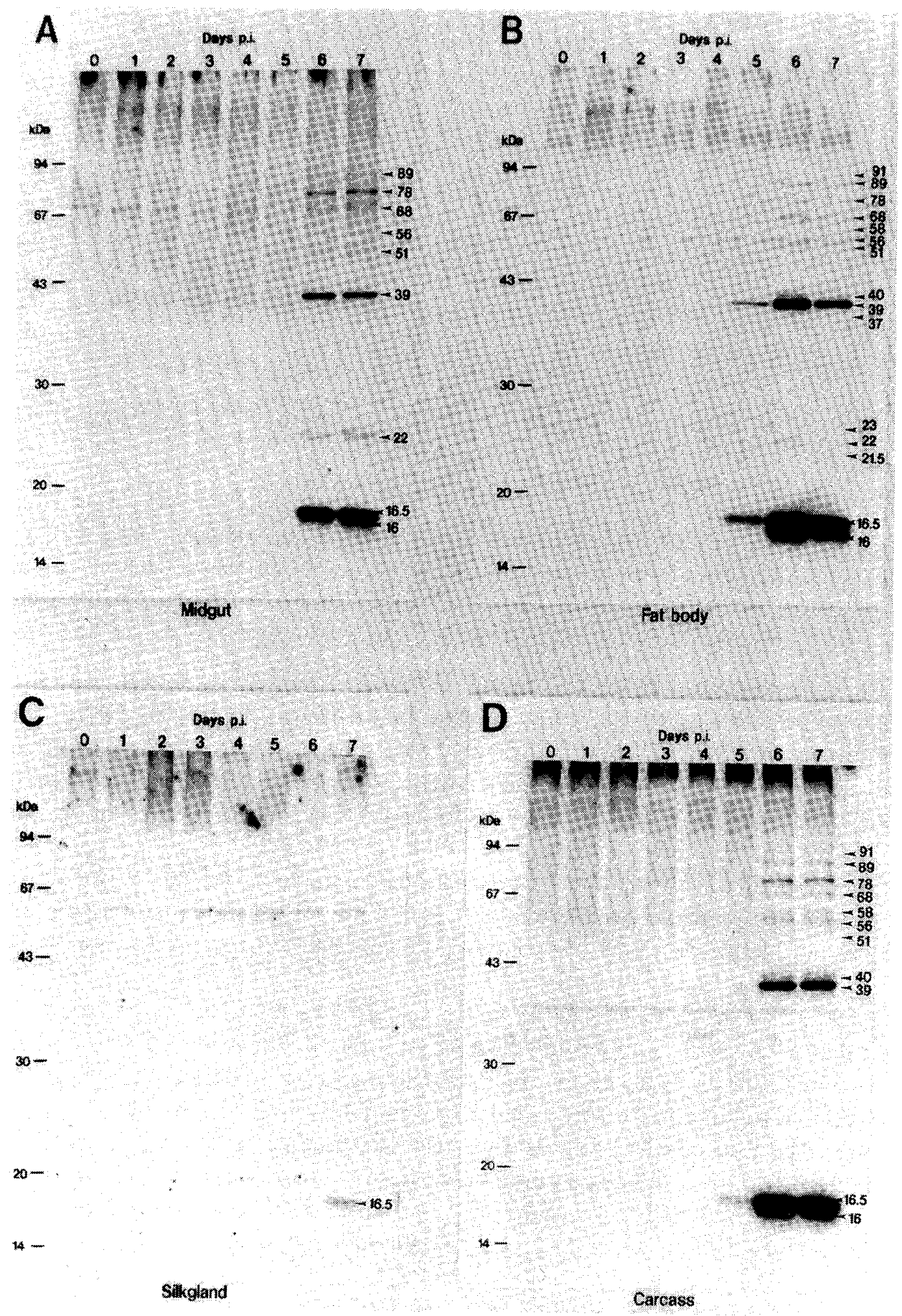

Fig. 5. Western blot analysis of virus-specific polypeptides in BmSNPV-infected larval tissues. Samples of protein $(20 \mu \mathrm{g})$ from the BmSNPV-infected midgut (A), fat body (B), silkgland $(\mathrm{C})$, and carcass $(\mathrm{D})$ at various times pi were resolved on $12.5 \%$ SDS-polyacrylamide gels, and subjected to Western blot analysis using anti-BmSNPV antiserum prepared in a rabbit as the primary antibody. The antibody-antigen complexes were detected with ${ }^{125} \mathrm{I}$-labeled goat anti-rabbit $\operatorname{IgG}$, and visualized by an imaging analyzer. The numbers on the left indicate MWs $\left(\times 10^{-3}\right)$ of the marker polypeptides. The numbers and arrowheads on the right indicate approximate MWs $\left(\times 10^{-3}\right)$ of the virus-specific polypeptides. 


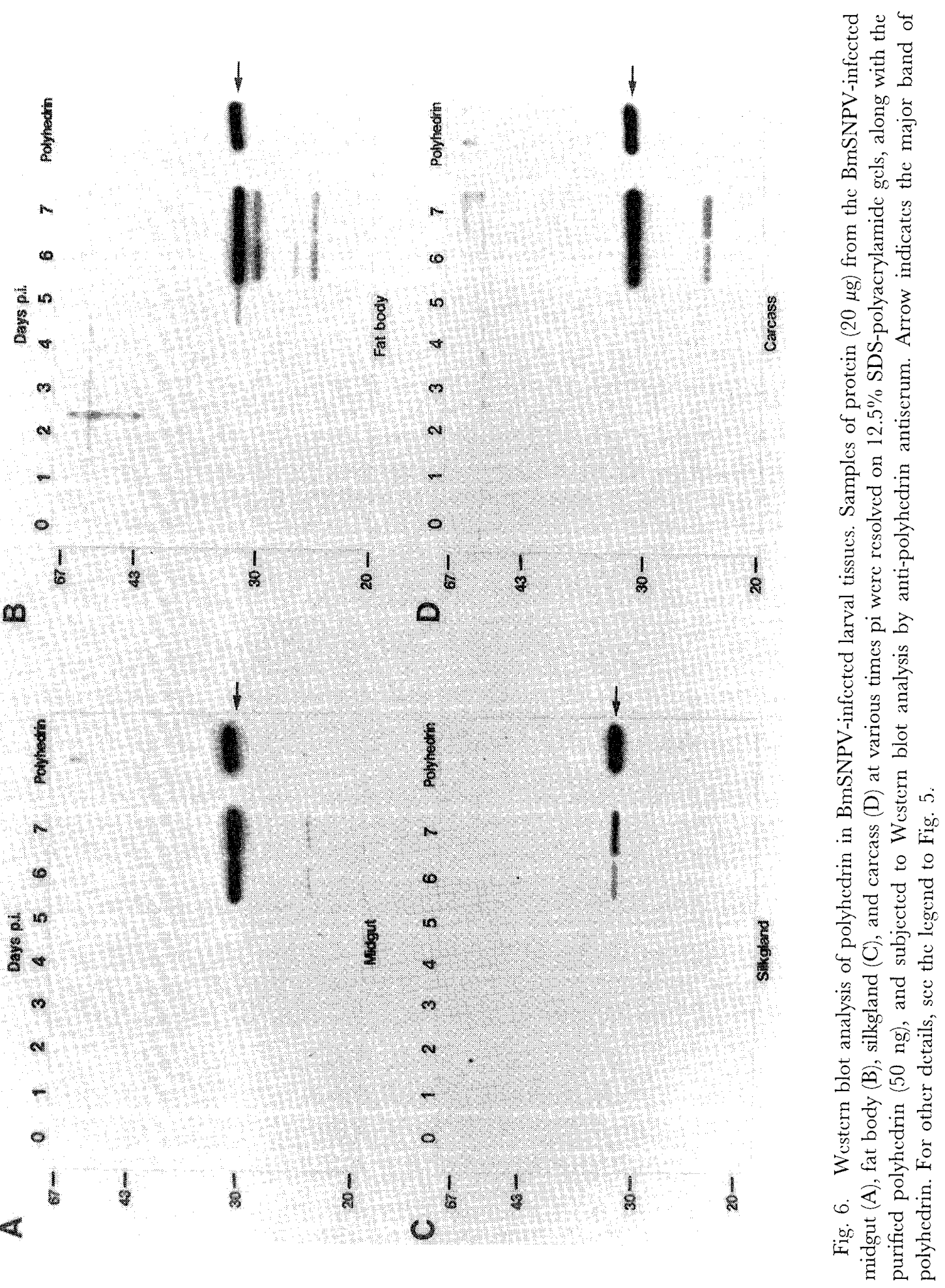


silkgland (Fig. 5). The polypeptide of $39 \mathrm{~K}$ which appeared at 5 days pi in the fat body and carcass, and at 6 days pi in the midgut is probably the major capsid polypeptide, based on its abundance and MW (SUGimori et al., 1990, 1991).

Polypeptides from BmSNPV-infected tissues were also analyzed by anti-polyhedrin antiserum. The Western blot showed that the major band of about $31 \mathrm{~K}$ was detected in all tissues examined and increased with the time pi (Fig. 6). The smaller bands which reacted with anti-polyhedrin antiserum probably represent degradation products of polyhedrin.

\section{DISCUSSION}

Baculovirus DNA polymerase gene ( $p o l)$ has been shown to express multiple species of transcripts in infected culture cells (TOMALSKI et al., 1988; BJORNSON et al., 1992; ChAEYCHOMSRI et al., 1995). In BM-N cells infected with BmSNPV, we found that at least seven different transcripts, with a common $3^{\prime}$ end, of approximately $3 \mathrm{~kb}$ in length are expressed from the BmSNPV pol (GHAEYchomSRI et al., 1995). These seven pol transcripts place their $5^{\prime}$ ends at $-119,-120,-122,-132,-133,-197$ and -334 relative to the translational initiation codon, that locate within or in the immediate vicinity of motif $5^{\prime}$ GCGTGCT-3', 5'-AGAGCGT-3' or 5'-GGCGGTGG-3'. The kinetics of the expression of each pol transcript in the BM-N cells change strikingly during BmSNPV infection, suggesting that the transcription of these pol transcripts is regulated differentially in infected cells. It is not known whether such heterogeneity of pol transcription is of any significance in tissuespecific regulation of viral pol expression in tissues infected with BmSNPV.

In the present study, we chose the midgut, fat body, silkgland and remaining carcass, which mainly consisted of hypodermis and cuticle, and analyzed the viral pol transcripts and DNA polymerase protein in these tissues during BmSNPV infection. The rationale for choosing these tissues is that the response to the BmSNPV infection has been suggested to vary considerably among these tissues. Even though no detailed comparative study has been reported on the yields of progeny virions and polyhedra among the infected tissues, it is presumed that the fat body is the major tissue of virus multiplication, while the silkgland is not a main target of the virus, as evidenced by low production of polyhedra (ARUGA et al., 1957,1963 ). A considerable amount of progeny virions is produced in the midgut, but only a few small polyhedra are formed (KANKE and IWASHITA, 1969).

Employing these tissues from BmSNPV-infected larvae, an RNase protection assay showed that among seven species of 3-kb viral pol transcript identified in BmSNPV-infected BM-N cells, only two species were expressed (Fig. 2). These two pol transcripts place their $5^{\prime}$ end at -119 (-119 transcript) and -334 (-334 transcript) relative to the translational initiation site, and corresponded to the predominant and largest species, respectively, among those identified in the BmSNPV-infected BM-N cells (CHAEYCHOMSRI et al., 1995), thus demonstrating no viral pol transcripts unique to larval tissues. The -119 transcript initiates at the A present 2 nt downstream of the motif $5^{\prime}$-GCGTGCT-3', whereas the -334 transcript initiates at the third $\mathrm{G}$ within the second octanucleotide motif 5'-GGCGGTGG-3' that is arranged as a direct repeat (CHAEYCHOMSRI et al., 1995). Transcripts initiating within or in the close vicinity of motif 5'-AGAGCGT-3', that serves as the transcriptional initiation sites of viral pol in the BmSNPV-infected BM-N cells as well as in the AcMNPV-infected Spodoptera frugiperda (SF) cells (TOMALSKi et al., 1988; ChaEychomsRi et al., 1995), were undetectable in the infected tissues. Kinetic evidence showed that in the fat body and carcass, the -334 transcript remained constant through 7 days pi, while the -119 transcript 
decreased at 7 days pi, indicating that BmSNPV pol used both motifs $5^{\prime}$-GGGTGCT- $3^{\prime}$ and $5^{\prime}$-GGCGGTGG-3' until 6 days pi but favored the motif 5'-GGGGGTGG-3' at 7 days pi. In addition, the relative abundance of -334 transcript to -119 transcript is higher in the carcass than in the fat body and midgut (Fig. 2). These results suggest that regulation of the expression of 3-kb viral pol transcripts is different not only between cultured cells and larval tissues but also among tissues in an infected larva. Taking into account the circumstantial evidence that baculovirus pol is transcribed by host RNA polymerase II (FuCHS et al., 1983; Huh and Weaver, 1990; Glocker et al., 1992), it is possible that the regulation of BmSNPV pol in the infected tissues is dependent on tissue-specific factor(s).

Besides the 3-kb viral pol transcripts, several viral pol transcript species larger than $3 \mathrm{~kb}$ were detected in considerable quantities in the midgut, fat body and carcass at 6 and 7 days pi (Fig. 1). In the fat body and carcass, the temporal pattern of the expression of these larger species is different from that of $3-\mathrm{kb}$ transcripts that are detected at 4 days pi and maintained through 7 days pi, suggesting that the expression of $3-\mathrm{kb}$ and larger species is regulated through different mechanisms in these tissues. Although such larger species have not been found in BmSNPV-infected BM-N cells (CHAEYchOMSR et al., 1995), a similar larger pol transcript of about 5-6 kb was observed in the AcMNPV-infected SF cells (TOMALSKI et al., 1988), indicating that expression of the larger species is not confined to larval tissues. It is possible that expression of the 5-6 kb transcript in AcMNPV-infected SF cells is negatively regulated by some factors of either viral or cellular origin that are produced de novo after virus infection, since the expression of 5-6 kb pol transcript is accentuated by treatment of AcMNPV-infected SF cells with a protein synthesis inhibitor, cycloheximide (TOMnLski et al., 1988). Whether the larger pol transcripts present in the BmSNPV-infected Bombyx larvae have any special function in the production of viral DNA is unknown.

Analyses by Northern blot hybridization and RNase protection assay showed that accumulation of BmSNPV pol transcripts was prominent in the fat body and carcass, less prominent in the midgut, and minor in the silkgland (Figs. 1, 2). Such differences in the abundance of pol transcripts among tissues coincide with the amount of DNA polymerase protein accumulated in the midgut, fat body and silkgland, suggesting the regulation of pol expression at the transcriptional level in these tissues. In the carcass, however, only a very little DNA polymerase protein was detected, in contrast to the abundance of pol transcripts (Figs. 1, 2 vs. Fig. 3). This may suggest that the expression of pol transcripts in the carcass is regulated at a posttranscriptional level. Alternatively, it is possible that the conditions of Western blot analysis utilized successfully for the midgut and fat body are not adequate for detection of viral DNA polymerase protein in the carcass.

In agreement with the earlier indication that BmSNPV is polyorganotrophic and possesses the ability to multiply in almost all tissues (WATANABE, 1975), analyses in the present study showed that not only viral DNA but also viral structural polypeptides and polyhedrin were present in all tissues examined (Figs. 4-6). The analyses also demonstrated that the abundance of these viral components differed among tissues examined, with their accumulation being most extensive in the fat body, moderate in the midgut and carcass, and least extensive in the silkgland. In these tissues, except for the carcass, the difference in the abundance of viral structural components is compatible with the difference in the expression of both pol transcripts and DNA polymerase protein, suggesting a possible role of viral pol expression or viral DNA synthesis in the regulation of late and very late gene expression.

Finally, our analysis showed that a considerable amount of polyhedrin accumulated in the infected midgut (Fig. 6). This result is in contrast to the observations under light and 
electron microscopy that polyhedra are rarely detectable in infected midgut cells which yield many progeny virions (KANKE and IWASHITA, 1969). Our result, thus, suggests that the morphogenesis of polyhedra rather than the production of polyhedrin is restrictive in infected midgut cells. A similar situation has been observed in the midgut of Trichoplusia ni larvae infected with $T . n i$ NPV in which only a few polyhedra with a few or no virions are formed, in spite of active production of polyhedrin (ADAMS and McCuINTOCK, 1991). The lack of ability of the midgut to produce a generous amount of polyhedra may be related to a unique role of the midgut during per os NPV infection, that is, the midgut is the primary target of NPV infection and provides budded progeny virions responsible for the establishment of systemic infection in the insect host (KEDDIE et al., 1989).

\section{ACKNOWLEDGEMENTS}

We thank Professor O. Yamashita, Dr. T. Yaginuma, and Dr. Y. SAto of our laboratory for their helpful discussion during this study. S.C. was supported by a scholarship from the Ministry of Education, Science and Culture of Japan. This work was supported in part by a Grant-in-Aid (No. 05660388) from the Ministry of Education, Science and Culture of Japan.

\section{REFERENCES}

Adams, J.R. and J.T. MCGuntock (1991) Nuclear polyhedrosis viruses of insects. In Atlas of Invertebrate Viruses (J.R. Adams and J.R. Bonami, eds.). CRC Press, Boca Raton, FL, pp. 89-204.

Aruga, H., S. Fukuda and N. Yoshitake (1963) Observations on a polyhedrosis virus within the nucleus of the silkgland cell of the silkworm, Bombyx mori L. J. Seric. Sci. Jpn. 32: 213-218.

Aruca, H., H. Watanabe, T. Hukuhara and Y. Iwashita (1957) Mechanism of the virus resistance in the silkworm, Bombyx mori. I. On the formation of the polyhedral body in the nucleus of the silk-gland cell. J. Seric. Sci. Jpn. 26: $1-8$.

Bjornson, R.M., B. Glocker and G.F. Rohrmann (1992) Characterization of the nucleotide sequence of the Lymantria dispar nuclear polyhedrosis virus DNA polymerase gene region. J. Gen. Virol. 73: 3177-3183.

Chaeychomsri, S., M. IKeda and M. Kobayashi (1995) Nucleotide sequence and transcriptional analysis of the DNA polymerase gene of Bombyx mori nuclear polyhedrosis virus. Virology 206: 435-447.

Chomczynski, P. and N. SAcchi (1987) Single-step method of RNA isolation by acid guanidinium thiocyanate-phenol-chloroform extraction. Anal. Biochem. 162: 156-159.

Crawford, A.M. and L.K. Miller (1988) Characterization of an early gene accelerating expression of late genes of the baculovirus Autographa califormica nuclear polyhedrosis virus. J. Virol. 62: 2773-2781.

Francki, R.I.B., G.M. Fauquet, D.L. Knudson and F. Brown (eds.) (1991) Glassification and nomenclature of viruses. Fifth report of the International Committee on Viruses. Arch. Virol. 2 (suppl.): 450.

Friesen, P.D. and L.K. Miller (1986) The regulation of baculovirus gene expression. Curr. Top. Microbiol. Immunol. 131: 31-49.

Fuchs, L.Y., M.S. Woods and R.F. WEAVER (1983) Viral transcription during Autographa californica nuclear polyhedrosis virus infection: a novel RNA polymerase induced in infected Spodoptera frugiperda cells. $J$. Virol. 48: 641-646.

Glocker, B., R.R. Hoopes, Jr. and G.F. Rohrmann (1992) In vitro transactivation of baculovirus early genes by nuclear extracts from Autographa californica nuclear polyhedrosis virus-infected Spodoptera frugiperda cells. J. Virol. 66: 3476-3484.

HuH, N.E. and R.F. WEAvER (1990) Identifying the RNA polymerases that synthesize specific transcripts of the Autographa califormica nuclear polyhedrosis virus. J. Gen. Virol. 71: 195-201.

Iatrou, K., K. Ito and H. Witkiewicz (1985) Polyhedrin gene of Bombyx mori nuclear polyhedrosis virus. $J$. Virol. 54: 436-445.

IrzukA, T., S. AOKI and C. Goto (1987) Identification of two nuclear polyhedrosis virus from the spotted cutworm, Xestia c-nigrum (Lepidoptera, Noctuidae). J. Fac. Agric. Hokkaido Univ. 63: 104-113.

Kanke, E. and Y. Iwashita (1969) Multiplication of the nuclear-polyhedrosis virus in the midgut epithelium 
of the silkworm, Bombyx mori L. J. Seric. Sci. Jpn. 38: 163-167.

Keddie, B.A., G.W. Aponte and L.E. Volkman (1989) The pathway of infection of Autographa califormica nuclear polyhedrosis virus in an insect host. Science 243: 1728-1730.

Kelly, D.C. (1981) Baculovirus replication: stimulation of thymidine kinase and DNA polymerase activities in Spodoptera frugiperda cclls infected with Trichoplusia ni nuclear polyhedrosis virus. J. Gen. Virol. 52: 313319.

Kobayashi, M. and S. Chaeychomsri (1993) Thermal inhibition of viral disease in the silkworm, Bombyx mori L. Indian J. Seric. 32: 1-7.

Kobayashi, M. and M. NAKAGAKI (1984) Effect of dissolution conditions of polyhedral inclusion bodies in sodium carbonate solution on the yield of nuclear polyhedrosis virus of the silkworm, Bombyx mori (Lepidoptera: Bombycidac). Appl. Entomol. Zool. 19: 280-287.

Kobayashi, M., M. Kotake, H. Sugimori, T. Nagamine and Z. Kajiura (1990) Identification of virusspecific polypeptides and translatable mRNAs in the isolated pupal abdomens of the silkworm, Bombyx mori, infected with nuclear polyhedrosis virus. J. Invertebr. Pathol. 55: 52-60.

LAEmml, U.K. (1970). Cleavage of structural proteins during the assembly of the head of bacteriophage T4. Nature (London) 227: 680-685.

Lu, A. and E.B. Carstens (1991) Nucleotide sequence of a gene essential for viral DNA replication in the baculovirus Autographa califormica nuclear polyhedrosis virus. Virology 181: 336-347.

MAedA, S. and K. Majima (1990) Molecular cloning and physical mapping of the genome of Bombyx mori nuclear polyhedrosis virus. J. Gen. Virol. 71: 1851-1855.

Maeda, S., S.G. Kamita and H. Kataoka (1991) The basic DNA-binding protein of Bombyx mori nuclear polyhedrosis virus: the existence of an additional arginine repeat. Virology 180: 807-810.

Mikhailov, V.S., J.O. Ataeva, K.A. Marlyev and P.K. Kullyev (1986) Changes in DNA polymerase activities in pupae of the silkworm Bombyx mori after infection with nuclear polyhedrosis virus. J. Gen. Virol. 67: 175-179.

Miller, L.K., J.E. Jewell and D. Browne (1981) Baculovirus induction of a DNA polymerase. J. Virol. 40: 305-308.

Nagamine, T., M. Kobayashi, S. SAGa and M. Hoshino (1991) Preparation and characterization of monoclonal antibodies against occluded virions of Bombyx mori nuclear polyhedrosis virus. J. Invertebr. Pathol. 57: $311-324$.

Nagamine, T., M. Shimomura, H. Sugimori and M. Kobayashi (1989) Titration of Bombyx mori (Lepidoptera: Bombycidae) nuclear polyhedrosis virus in a Bombyx mori cell line. Appl. Entomol. Zool. 24: 235237.

O'Reilly, D.R., A.M. Crawford and L.K. Miller (1989) Viral proliferating cell nuclear antigen. Nature (London) 337: 606.

Shmbrook, J., E.F. Fritsch and T. Maniatis (1989) Molecular Cloning: A Laboratory Manual, 2nd ed. Cold Spring Harbor Laboratory, Cold Spring Harbor, NY.

Sugimori, H., T. Nagamine and M. Kobayashi (1990) Analysis of structural polypcptides of Bombyx mori (Lepidoptera: Bombycidae) nuclear polyhedrosis virus. Appl. Entomol. Zool. 25: 67-77.

Sugimori, H., T. Nagamine and M. Kobayashi (1991) Protein synthesis in BM-N cells infected with Bombyx mori nuclear polyhedrosis virus. J. Invertebr. Pathol. 58: 257--268.

Tomalski, M.D., J. Wu and L.K. Miller (1988) The location, sequence, transcription, and regulation of a baculovirus DNA polymerase gene. Virology 167: 591-600.

VAN BeEk, N.A.M., P.H. Flore, H.A. WoOd and P.R. Hoghes (1990) Rate of increase of Autographa califormica nuclear polyhedrosis virus in Trichoplusia $n i$ larvae determined by DNA: DNA hybridization. J. Invertebr. Pathol. 55: 85-92.

WANG, X. and D.C. KELLY (1983) Baculovirus replication: Purification and identification of the Trichoplusia ni nuclear polyhedrosis virus-induced DNA polymerase. J. Gen. Virol. 64: 2229-2236.

Watanabe, H. (1975) Variation in the number of nucleocapsid within the envelope of nuclear polyhedrosis virus multiplied in different tissues of the silkworm, Bombyx mori. J. Seric. Sci. Jpn. 44: 497-498. 